\title{
Cardiovascular changes and mental health problems in pregnancy
}

\author{
Roxana Mihaela Barbu, Cristina-Maria Gavrilescu, Cristina Oprişa, \\ Cătălin Pohaci-Antonesei, Ioana Maria-Gavrilescu, Luiza Pohaci-Antonesei
}

\begin{abstract}
Roxana Mihaela Barbu - MD, PhD, University of Medicine and Pharmacy „Grigore T. Popa”, $2^{\text {nd }}$ Morpho-Functional Department, Iasi, Romania, Specialist in Clinical Pharmacology Cristina-Maria Gavrilescu - MD, PhD, University of Medicine and Pharmacy „Grigore T. Popa”, $1^{\text {st }}$ Medical Department, Iasi, Romania, Senior in Internal Medicine, Specialist in Geriatrics and Gerontology, Specialist in Clinical Pharmacology

Cristina Oprişa - MD, PhD, University of Medicine and Pharmacy „Grigore T. Popa” $2^{\text {nd }}$ MorphoFunctional Department, Iasi, Romania, Specialist in Occupational Medicin e

Cătălin Pohaci-Antonesei - MD, PhD, University of Medicine and Pharmacy „Grigore T. Popa” $2^{\text {nd }}$ Morpho-Functional Department, Iasi, Romania, Specialist in Occupational Medicine

Ioana-Maria Gavrilescu - MD, Resident in Psychiatry, "Socola" Institute of Psychiatry, Iasi, Romania

Luiza Pohaci-Antonesei - MD, PhD, University of Medicine and Pharmacy „Grigore T. Popa” $2^{\text {nd }}$ Morpho-Functional Department, Iasi, Romania, Specialist in Pediatric
\end{abstract}

\section{ABSTRACT}

Pregnancy is a special new condition for the maternal body in which all of the systems have to undergo changes in order to sustain the development of the fetus. The changes that appear during pregnancy have essential purposes such as the adjustment of maternal metabolism to sustain fetal development and growth, to prepare for labor, birth and breastfeeding. Pregnancy is characterized by specific cardiovascular changes that start within the first weeks of gestation. The effects of pregnancy on the maternal body are major and these involve the cardiovascular system through all the hemodynamic, hormonal and emotional changes that occur. As the pregnancy develops, the quantity of blood that the mothers' heart has to pump grows proportionally. The cardiac output increases, the volemia grows and the heart has to undergo an extra effort to be able to maintain the functionality of organs and systems. The birth in itself means a series of neuro-endocrinological and emotional changes on the maternal body and the cardiac monitoring is vital, especially for the women that already have cardiovascular problems. Pregnancy is often considered a positive period of time in the life of a woman, in which joy, enthusiasm and other positive emotions are prominent. Still, the hormonal and cardiovascular changes that the body of the future mother undergoes can make pregnancy a time of emotional vulnerability and can present a challenge for her overall wellbeing. Mental health in pregnancy can sometimes be neglected by the medical system, 
\% although it is essential for the pregnant woman. The cardiovascular pathology that appears during birth can trigger some psychiatric disorders such as depression or anxiety. The increase in cardiac output, tachycardia and hypertension can be the primary mechanisms of cardiac compensation in the peripartum period. These can be the causes of cardiac decompensation when an associated pathology is present.

\section{KEYWORDS:}

Pregnancy, cardiovascular changes, mental health.

\section{INTRODUCTION \\ PHYSIOLOGICAL CHANGES DURING PREGNANCY}

A series of haemodynamic, homeostatic and metabolic physiological changes occur during pregnancy. These changes have the role of adapting the mother's body to the fetus' needs and could interact with the diagnostic methods and pharmacological therapy. The hormonal changes that induce the relaxation of the smooth muscles, followed by the formation of the placenta and fetal circulation determines an increase in the blood volume slowly beginning from the 5th week of gestation. The increase is of $50 \%$ when getting to the term and is higher in multiple pregnancies. Both the systemic vascular resistence and the blood pressure drop and the heart rate increases by 10-20 beats per minute. The result is an increase of $30-50 \%$ in the cardiac output, increase that is mostly done by the increase in the systolic volume. The failure of these adaptations manifests through resting tachycardia; this shows a decreased cardiac reserve that is damaging as the left ventricle filling is diminished. Giving birth implies an extra increase of cardiac output and blood pressure, especially during uterine contractions, and an increase in the oxygen consumption. These haemodynamic changes are highly influences by the method of birth. The cardiac output is also increased in the early postpartum period, because the blood that is brought into circulation by the uterine contractions determines a preload increase (1, 2). A refractory angiotensin state usually occurs during pregnancy, this being because of a reduced response to the vasopresor effect of angiotensin, even though the renin activity, the reninic substrate, the angiotensin II and aldosterone are increased. The vena cava syndrome is also mentioned as appearing due to the compression of the inferior vena cava by the uterus in the dorsal decubitus position, thus decreasing the venous return, proning the pregnant woman to fainting. The venous system is undergoing a series of adjustments: the venous walls are distended; the compression given by the uterus on the inferior vena cava and the iliac veins increase the venous pressure in the lower limbs, contributing to the occurence of varicose veins and in the hemorrhoidal plexus with the occurence of hemorrhoids. One of the essential adaptative adjustments in pregnancy is the fact that the peripheral vascular resistence decreases. The haemodynamic changes go back to the normal preexistent state in 1-3 days in most women, but this can take up to a week $(3,4)$. In the case of women that do not have a preexistent cardiac disease, the adapting mechanisms during pregnancy are physiological and no pathological aspects appear before, during or after birth. Sometimes, pregnancy can however become the trigger mechanism of a cardiac pathology in women that have previous unknown limitations of the cardiac reserve. Cardiac problems that are diagnosed before or during the pregnancy can negatively influence the mental state of the pregnant woman and can sometimes lead to psychiatric disorders $(4,5)$. 
Bulletin of Integrative Psychiatry $\bigcirc$ New Series OJune $2020 \bigcirc$ Year XXVI ONo. 2 (85)/85

Social expectations from pregnant women and new mothers can cause anxiety and stress among them. Even well-intentioned persons from within the family, friends or strangers can criticise certain practices or diets of pregnant women and can many times offer unsolicited pieces of advice. Consequently, these women may have the tendency to feel irritated, frustrated or furious and some may even doubt their capacity of becoming good mothers $(6,7)$. A pregnant woman can undergo mood swings, fears, anxiety, can forget things or can deal with body dismorphia. Women that went through depression or anxiety before their pregnancy are more prone to mental health problems in this period of time. When these problems occur during pregnancy or after birth, professional mental health advice is often needed. Counseling before and during pregnancy is vital. This should include genetic counseling, genetic testing for cardiac hereditary disease and a psychological consultation (8).

Many studies have discovered that a quarter of pregnant women that have cardiovascular disease deal with mental health issues during their pregnancy. Statistics show that 14 to $23 \%$ of pregnant women deal with prenatal depression and that 1 in 7 women will undergo depression in the time between a year before and a year after giving birth. Still, this disorder can many times remain undiagnosed either because of some similarities between pregnancy symptoms and depression symptoms or because of several myths that continue to surround the depression diagnosis. The results of these studies also underline the importance of the mothers' mental health for the proper neurocognitive and emotional development of the baby $(9,10)$.

\section{PREGNANCY AND THE MENTAL HEALTH ISSUES}

Even though nowadays mental health issues are worldwide being addressed far better than before, in Romania these problems are still considered intimate, taboo things that people often don't talk about. In the more developed countries, mental health issues are treated as seriously as the physical health problems, but in our country this change of perspective has only just begun in the last few years. The stigma is still very high for psychiatric or psychological issues and the cultural attitude is that even if one searches for specialized help to address the problem, one must not talk about it. Still, most of the times, this exact attitude is the one that stops people that are dealing with such problems to search for help (11).

Statistics published by the World Health Organization show that one in ten pregnant women is suffering or will suffer from a mental health issue. Also, studies show that certain issues regarding mental health in pregnancy can also be a predictor for the mental health of the mother after giving birth $(10,12)$.

It is estimated that $10-15 \%$ of the pregnancies will lead to miscarriage. These women don't always have the support to process this psychological and physical trauma if they don't go to counseling with a psychologist or psychotherapist. The specialized psychological support given in miscarriages is the same as the one given in experiencing the loss of a family member and experts recommend for both partners to pass through the grief stages to be able to integrate and overcome this situation (13).

The disease management during pregnancy must address both the well-being of the mother and of the fetus. Counseling and 
ндндн

management of the fertile women who may have cardiovascular and psychiatric illnesses should start long before the actual pregnancy. Interdisciplinary teams should be created for the management of these issues and the high risk women should be treated in specialized centers (14).

\section{PREGNANCY - AN EMOTIONALLY VULNERABLE TIME}

Pregnancy is often considered a positive period of time in a woman's life, in which joy, enthusiasm and other positive emotions are prominent. Still, the hormonal and cardiovascular changes that the body of the future mother undergoes can make pregnancy a time of emotional vulnerability (15). Some factors that could heighten this emotional vulnerability for the future mother include: changes in body image, especially in mothers with eating disorders; financial stress; unpleasant pregnancy symptoms such as morning sickness, vomiting, muscular cramps, constipation, discomfort and pain that negatively influence the mood; the lack of social support; pressure from society; pregnancy obtained due to different fertility treatments, aspect that can contribute to a higher anxiety of the mother regarding the pregnancy and the baby's health; possible pregnancy complications; a personal history of a psychiatric issue before or during the pregnancy; miscarriage; problems with a previous pregnancy or birth; relationship problems or the status of a single mother; unwanted pregnancy; pregnancy at a young age; other stressful life events during pregnancy.

Symptoms of certain mental health issues are the most common complications in birth , such as: $15-20 \%$ of women go through severe anxiety or postpartum depression; two thirds of the mothers that are diagnosed postpartum with a mental health issue have started to have behavioral changes during the pregnancy and $60 \%$ of them had pregnancy complications such as gestational diabetes; stress experienced throughout the pregnancy, especially post-traumatic stress, was found to be connected to premature birth, small weight at birth and risky behavior during pregnancy; many women feel "the sadness of birth" for one-two weeks postpartum, but when this doesn't disappear and other feelings appear such as hopelessness, negative thoughts about self and the newborn child, loss of appetite, these could be signs of a more serious illness; postpartum psychosis is a rare but very serious disorder, appearing abruptly in the first two weeks postpartum and being characterized by mood swings, paranoid delusions and hallucinations, with a suicide rate of $5 \%$ and an infanticide rate of $4 \%$ (16, 17).

\section{PSYCHIATRIC DISORDERS DURING PREGNANCY}

Perinatal psychopathology studies multiple aspects such as the psychological difficulties and psychiatric disorders that can occur during pregnancy and in the postpartum period. The importance of the perinatal psychopathology derives from the consequences on the early mother-child relationship, the psychotropic medication that can be administered during pregnancy and during breastfeeding and the risks that can arise from abruptly stopping the treatment at the beginning of the pregnancy (18).

Antenatal depression is a certain risk factor of $10-50 \%$ for postnatal depression. Sometimes an episode of antenatal depression can represent the first episode of bipolar disorder, especially when there is a particular familial history, or can simply be a relapse. Antenatal depression is present in $23 \%$ of pregnant women and $13 \%$ of them take an antidepressant during pregnancy. During the 
s

pregnancy, many types of depression, including masked depression and neurotic depression can appear and their intensity may vary $(19,20)$.

Postnatal depression is a serious illness that has important consequences on the mother and the child's health. From the existent statistics, 25 to $30 \%$ of women that give birth can experience postnatal depression. Even though this is not a new discovery in the medical field or in the knowledge of the general population, there is still a resistance in accepting and treating this pathology. One of the factors that are correlated with postnatal depression is the low social support given to the woman by her partner and her social circle. A sudden change in lifestyle, emotional and physical stress and uncertainty in the new role as a mother have been shown to be aggravating factors of depression A proper social support system can reduce or even avoid the onset of postnatal depression $(21,22)$.

Pregnancy-induced anxiety is significantly correlated with a higher risk of obstetrical complications. The highest levels of anxiety are experienced in the between the $9^{\text {th }}$ and the $12^{\text {th }}$ week of pregnancy, and right before giving birth. The anxiety that the pregnant woman feels is in regard to the baby that will be born, to the health issues that may appear, to labor and to her own capacity of taking care of the newborn child. Although anxiety is frequently felt during pregnancy, panic attacks are less often and the depressive tendencies are not usually long-lasting. Still, if panic attacks are experienced, the risk of a premature birth or of a birth of a child with hypotrophy increases (23).

Denial of pregnancy is the pathology characterized by the fact that the woman isn't aware of the fact that she is pregnant. In this case, the pregnancy symptoms are absent, the weight gain is minimal and the woman doesn't have characteristic morphological changes. This phenomenon can be encountered in women of all ages and of all social and cultural backgrounds and does not only affect primiparous ones. In only $50 \%$ of cases of pregnancy denial, an underlying psychiatric condition is discovered. A partial denial is diagnosed when the pregnancy is discovered before birth, but otherwise the woman suffers from total denial, and in this latter case the infanticide risk is high. The reverse phenomenon is known as pseudocyesis or phantom pregnancy, the case in which a woman with fertility problems that wishes for a pregnancy can become convinced of the fact that she is pregnant, even experiencing amenorrhea, weight gain, abdominal distention and subjective sensations of fetal movements. One percent of women with this condition can also experience a false labor (24).

\section{CONCLUSIONS}

Pregnant women go through certain hormonal and emotional changes and that makes them vulnerable to mental health issues. Also, the hope that pregnancy is a happy moment for them can sometimes be unrealistic. Women should be monitored and asked about their emotional state thoughout their pregnancy and after birth by medical personnel that can manifest objectivity and support.

Disease management during pregnancy must tend both to the well-being of the mother and of the baby. Counseling and management of certain suspected cardiovascular and psychiatric issues should begin long before the beginning of the pregnancy and should be done by interdisciplinary teams. High-risk women should be treated in specialized centres. The counseling, that should start 
(2) before pregnancy and should be maintained throughout its duration, has to include genetic advice, genetic testing of hereditary cardiac disease and a psychological consult.

Perinatal psychiatry is a newer discipline consisting of elements from pedopsychiatry, adult psychiatry, obstetrics and pediatrics. This branch has a role in identifying the high risk population regarding psychiatric issues and in trying to manage this pathology.

Both cardiovascular and psychiatric disorders that appear during pregnancy represent a public health problem because of their prevalence, of their effect on both the mother and the child and because of the fact that they are still poorly recognized.

In conclusion, the counseling and social support for the woman with cardiovascular and psychiatric issues should be mandatory before conception and should be maintained throughout pregnancy and in the postpartum period in order to improve the quality of life of both the future mother and the future child.

\section{ACKNOWLEDGEMENTS AND DISCLOSURES}

The authors state that they are no declared conflicts of interest regarding this paper.

\section{REFERENCES}

1. Braunwald E, Heartdisease - a Textbook of Cardiovascular Medicine, Ed.W.B. Saunders, 6th Edition, 2001 ; 112:120.

2. Ruys TP, Roos-Hesselink JW, Hall R, Subirana-Domenech MT, Grando-Ting J, Estensen M, Crepaz R, Fesslova V, Gurvitz M, De Backer J, Johnson MR, Pieper PG. Heart failure in pregnant women with cardiac disease: Data from the ropac. Heart 2014;100:231-238.

3. Arsenesescu C., Tratamentul rational al bolilor cardiovasculare majore, editura Polirom, 2008 ; 45-52.

4. Mitu F., Actualităţi în semiologia respiratorie şi cardiovasculară, Editura Gr. T. Popa Iaşi, 2011; 63-71.

5. Van Hagen IM, Boersma E, Johnson MR, Thorne SA, Parsonage WA, Escribano Subias P, Lesniak-Sobelga A, Irtyuga O, Sorour KA, Taha N, Maggioni AP, Hall R, Roos-Hesselink JW. Global cardiac risk assessment in the registry of pregnancy and cardiac disease: Results of a registry from the European Society of Cardiology. Eur J Heart Fail 2016;18:523-533.

6. American College of Obstetricians and Gynecologists Committee on Obstetric Practice. Committee Opinion No. 630: Screening for perinatal depression. Obstetrics \& Gynecology. 2015;125:1268.

7. Knight M, Nair M, Tuffnell D, Kenyon S, Shakespeare J, Brocklehurst P, Kurinczuk JJ, (Eds.) on behalf of MBRRACE-UK. Saving lives, improving mothers' care - surveillance of maternal deaths in the UK $2012-14$ and lessons learned to inform maternity care from the uk and ireland confi dential enquiries into maternal deaths and morbidity 2009-14. Oxford: National Perinatal Epidemiology Unit, University of Oxford; 2016.

8. O'Connor E, et al. Primary care screening for and treatment of depression in pregnant and postpartum women. Journal of the American Medical Association. 2016;315:388.

9. Grigoriadias S. Unipolar major depression during pregnancy: Epidemiology, clinical features, assessment, and diagnosis. https://www.uptodate.com/contents/search. Accessed Aug. 5, 2019.

10. Biaggi A, et al. Identifying the women at risk of antenatal anxiety and depression: A systematic review. Journal of Affective Disorders. 2016;191:62.

11. Yonkers KA, Wisner KL, Stewart DE, Oberlander TF, Dell DL, Stotland N, et al. The management of depression during pregnancy: a report from the American Psychiatric Association and the American College of Obstetricians and Gynecologists. Obstet Gynecol. 2009;114(3):703-13.

12. Andersson L, Sundström-Poromaa I, Wulff M, Aström M, Bixo M. Neonatal outcome following maternal antenatal depression and anxiety: a population-based study. Am J Epidemiol. 2004;159(9):872-81.

13. Dayan J, Creveuil C, Herlicoviez M, Herbel C, Baranger E, Savoye C, et al. Role of anxiety and depression in the onset of spontaneous preterm labor. Am J Epidemiol. 2002;155(4):293-301.

14. Bennett HA, Einarson A, Taddio A, Koren G, Einarson TR. Depression during pregnancy: overview of clinical factors. Clin Drug Investig. 2004;24(3):157-79.

15. Bonari L, Pinto N, Ahn E, Einarson A, Steiner M, Koren G. Perinatal risks of untreated depression during pregnancy. Can J Psychiatry. 2004;49(11):726-35. 

16. Andersson L, Sundström-Poromaa I, Wulff M, Aström M, Bixo M. Implications of antenatal depression and anxiety for obstetric outcome. Obstet Gynecol. 2004;104(3):467-76.

17. Swallow BL, Lindow SW, Masson EA, Hay DM. Psychological health in early pregnancy: relationship with nausea and vomiting. J Obstet Gynaecol. 2004;24(1):28-32.

18. Zuckerman B, Amaro H, Bauchner H, Cabral H. Depressive symptoms during pregnancy: relationship to poor health behaviors. Am J Obstet Gynecol. 1989;160(5 Pt 1):1107-11.

19. Cohen LS, Altshuler LL, Harlow BL, Nonacs R, Newport DJ, Viguera AC, et al. Relapse of major depression during pregnancy in women who maintain or discontinue antidepressant treatment. JAMA. 2006;295(5):499-507.

20. Koren G, Nordeng H. Antidepressant use during pregnancy: the benefit-risk ratio. Am J Obstet Gynecol. 2012;207(3):157-63. Epub 2012 Feb 21.

21. Jimenez-Solem E, Andersen JT, Petersen M, Broedbaek K, Jensen JK, Afzal S, et al. Exposure to selective serotonin reuptake inhibitors and the risk of congenital malformations: a nationwide cohort study. BMJ Open. 2012;2(3):e001148. doi: 10.1136/bmjopen-2012-001148.

22. Nulman I, Rovet J, Stewart DE, Wolpin J, Gardner HA, Theis JG, et al. Neurodevelopment of children exposed in utero to antidepressant drugs. N Engl J Med. 1997;336(4):258-62.

23. Gedeon C, Koren G. Gestational changes in drug disposition in the maternal-fetal unit. In: Koren G, editor. Medication safety in pregnancy and breastfeeding. New York, NY: McGraw Hill; 2007. pp. 5-12.

24. Regitz-Zagrosek V. et al. 2018 ESC Guidelines for the management of cardiovascular diseases during pregnancy. Eur Heart J 2018, 1-83.

\section{Correspondence:}

Cristina-Maria Gavrilescu,

MD, PhD, University of Medicine and Pharmacy „Grigore T. Popa”, 1st Medical Department, Iasi, Romania, Senior in Internal Medicine, Specialist in Geriatrics and Gerontology, Specialist in Clinical Pharmacology, cristina.gavrilescu@umfiasi.ro

Submission: 30 mar 2020

Acceptance: 19 may 2020 